\title{
SODIUM NITROPRUSSIDE-INDUCED HYPOTENSION AND RENAL BLOOD FLOW*
}

\author{
K.M. Leighton, C. Bruce, and B.A. MacLeod
}

SODIUM NITROPRUSSiDE relaxes the smooth muscle of resistance vessels and is employed to reduce arterial pressure during surgery. ${ }^{1}$ The major hazard of induced hypotension is hypoperfusion and one organ at particular risk is the kidney.

It seemed pertinent, therefore, to study the effect of nitroprusside-induced hypotension upon renal blood flow during halothane anaesthesia.

\section{METHODS}

Five mongrel dogs were studied in ten experiments.

The dogs were prepared under anaesthesia with halothane in the manner which has been described elsewhere. ${ }^{2}$ Briefly, Doppler ultrasonic flow probes were placed around the left renal artery of each animal and the leads from the probes were exteriorized on the dorsum of the neck. Flow probes were precalibrated in vitro using a variable volume pump, polyethylene tubing, and blood. A linear response was obtained from zero flow to $180 \mathrm{ml} / \mathrm{min}$.

The animals were permitted to recover for at least four days. They were then fasted for 15 hours, but allowed free access to water. Anaesthesia was then induced with thiopentone $(20 \mathrm{mg} / \mathrm{kg}$ ) and following tracheal intubation the animals were ventilated with oxygen and halothane by means of a Bird Mark 4 ventilator.

End-tidal concentrations of halothane were monitored by a Beckman (LB2) analyser.

Renal blood flow was measured by the Doppler flow meter. ${ }^{3}$ Percutaneous femoral artery cannulation permitted measurement of arterial pressure (Statham transducer P23AC) and blood gases (Radiometer PHM71). Ventilation was controlled to maintain $\mathrm{Pa}_{\mathrm{O}_{2}}$ greater than $100 \mathrm{~mm} \mathrm{Hg}, \mathrm{Pa}_{\mathrm{CO}_{2}} 30-40 \mathrm{~mm} \mathrm{Hg}$ and $\mathrm{pH}$ 7.35-7.46.

Rectal temperature was maintained at $39^{\circ} \mathrm{C}$ by means of a thermostatically controlled water blanket.

Approximately 40 minutes after the induction of anaesthesia, when blood pressure, renal blood flow, blood gases and end-tidal halothane concentration were stable, sodium nitroprusside was administered by intravenous infusion $(50 \mu \mathrm{g} / \mathrm{ml}$ ) at a rate of 2.5 to $3 \mu \mathrm{g} / \mathrm{kg} / \mathrm{min}$. Mean arterial pressure was reduced to approximately $50 \mathrm{~mm} \mathrm{Hg}$. This was maintained for at least 12 minutes.

Departments of Anaesthesia and Pharmacology, Faculty of Medicine, The University of British Columbia, Vancouver, B.C. V6T 1W5.

${ }^{*}$ Supported by a grant-in-aid of research from The British Columbia Heart Foundation. 

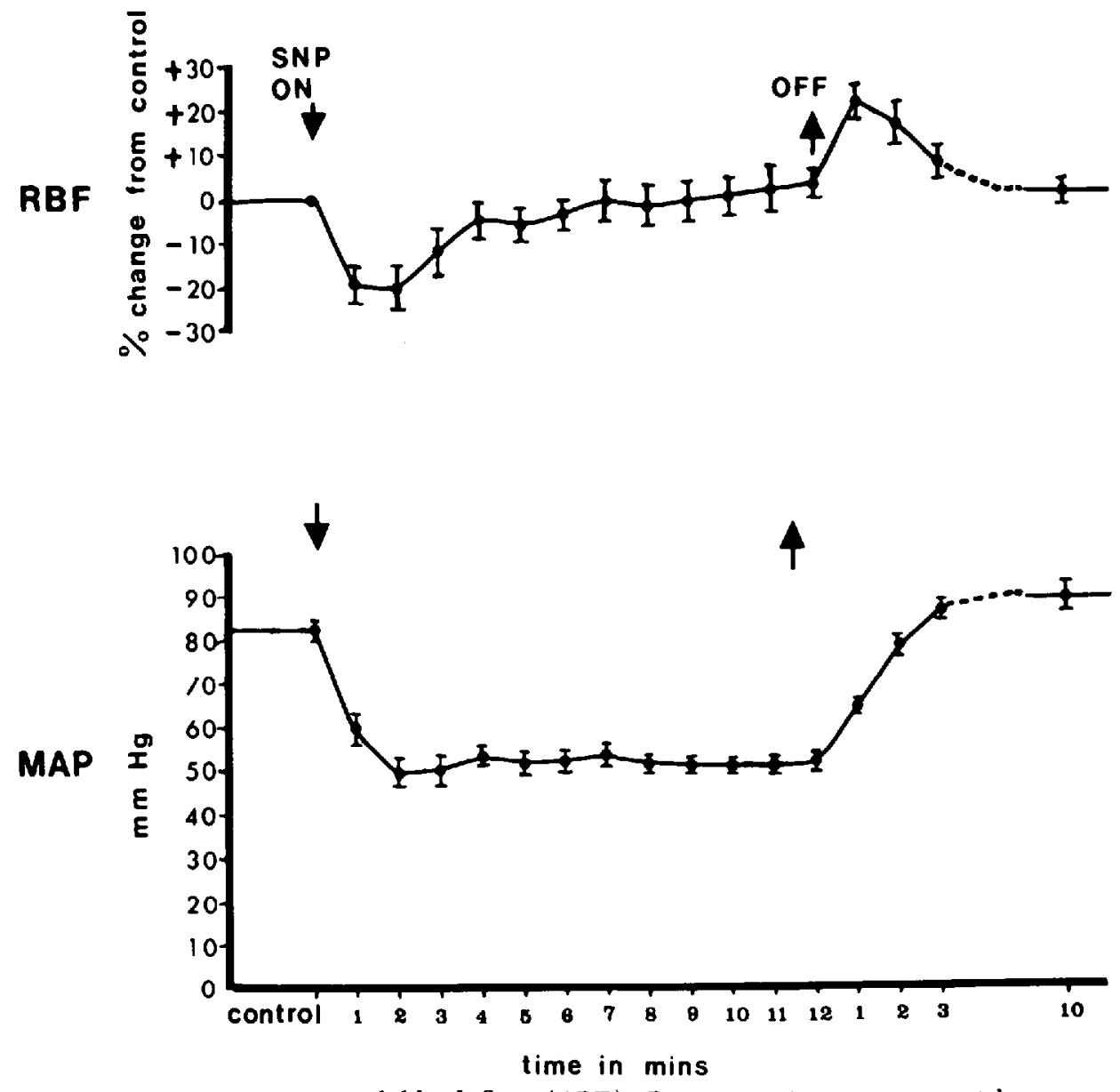

Figure 1. Top tracing, renal blood flow (RBF). Bottom tracing, mean arterial pressure (MAP). SNP = sodium nitroprusside. Ten experiments in five dogs. Standard errors are indicated. Note return of renal blood flow towards control levels in spite of hypotension produced by sodium nitroprusside.

\section{Results}

When mean arterial pressure was reduced below control levels, renal blood flow also fell. The decrease was transient, however, and blood flows returned to prehypotensive levels within six minutes. This restitution of flow occurred even at mean arterial pressures of $50 \mathrm{~mm} \mathrm{Hg}$.

The results of ten experiments in five dogs are shown in Figure 1. Figure 2 shows a typical response in one animal.

\section{Discussion}

The kidney normally maintains constant renal blood flow in spite of a reduction in mean arterial pressure. It is generally held that this autoregulation fails at pressures lower than $80 \mathrm{~mm} \mathrm{Hg}$ in man and experimental animals. ${ }^{+}$The results which we report show that autoregulation of renal blood flow persists during 


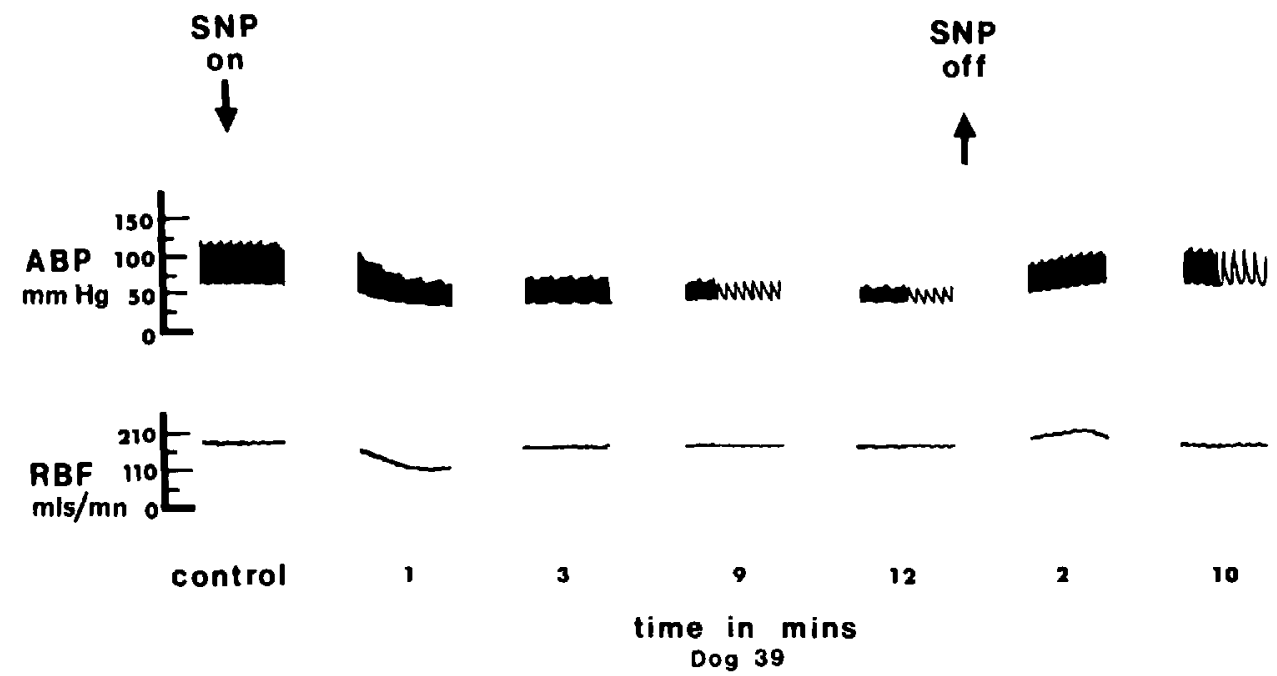

Frgune 2. Dog 39. ABP = arterial blood pressure. $\mathrm{RBF}=$ renal blood flow. Note transient fall in renal blood flow with return to near control figure.

hypotension induced by sodium nitroprusside in dogs anaesthetized with halothane. It is remarkable that this autoregulation operates at arterial pressures $(50 \mathrm{~mm} \mathrm{Hg}$ ) at which this function of the kidney is normally impaired.

The accuracy of the Doppler ultrasonic method for measuring blood flow has been demonstrated by Franklin ${ }^{5}$ and Vatner and Smith. ${ }^{6}$ The method appears to compare favorably with electromagnetic techniques ${ }^{\tau}$ and it has the advantage of baseline stability over the latter method.

Bastron and Kalonyanides ${ }^{8}$ observed in dogs that a reduction in arterial pressure by sodium nitroprusside to approximately $60 \mathrm{~mm} \mathrm{Hg}$ led to a decreased inulin and PAH clearance. Wang, et al., ${ }^{9}$ on the other hand, demonstrated that nitroprusside did not reduce renal blood flow in dogs. However, the latter authors reduced mean arterial pressures no lower than $90 \mathrm{~mm} \mathrm{Hg}$. Both groups of investigators used barbiturate or barbiturate-chloralose anaesthesia. Barbiturates are known to affect renal haemodynamics. ${ }^{10,11}$ Inulin and PAH clearance do not measure renal blood flow directly and altering perfusion pressures and low urine flows may make the data difficult to interpret.

The surprising response of the kidney to sodium nitroprusside which we report lacks an explanation at present. However, if nitroprusside can maintain renal perfusion in the presence of marked hypotension, as these results appear to indicate, then this agent may afford significant protection to the kidney during hypotension induced with the drug and in other low flow hypotensive states such as cardiopulmonary by-pass.

\section{SUMMARY}

Hypotension produced by sodium nitroprusside during halothane anaesthesia in a series of experiments in dogs was accompanied by the maintenance of renal blood flow. Renal blood flow was maintained at levels of systemic pressure at which flow is customarily reduced in man and experimental animals. The signi- 
ficance of this observation is the possibility that sodium nitroprusside has a protective effect on the kidney, not only in states of deliberate hypotension, but in other low flow states where renal perfusion and function may be compromised.

\section{RÉSUMÉ}

Le débit sanguin rénal s'est maintenu chez le chien (anesthésié à l'halothane), amené en hypotension artérielle au moyen de nitroprussiate de sodium, et ceci, à des niveaux de pression où l'on voit d'ordinaire chez l'homme et chez l'animal une diminution de débit rénal. Cette observation suggère la possibilité que le nitroprussiate puisse avoir une action protectrice sur le rein, non seulement dans le cas d'hypotension contrôlée, mais également dans les états de base débit alors que la perfusion et la fonction rénale sont compromises.

\section{REFERENCES}

1. Taylor, T.H., Styles, M., \& Lamming, A.J. Sodium nitroprusside as a hypotensive agent in general anaesthesia. Brit. J. Anaes. 42: 859 (1970).

2. Leighton, K.M., Koth, B., \& Wenkstenn, B.K. Autoregulation of renal blood flow: alteration by methoxyflurane. Canad. Anaes. Soc. J. 20: 173 (1973).

3. Leighton, K.M. Studies on the effects of succinylcholine upon the circulation of the anaesthetized dog. Canad. Anaes. Soc. J. 18: 100 (1971).

4. Selkurt, E.W. Renal circulation. Handbook of Physiology, Section 2, Vol. II, p. 1489 (1963).

5. Franklin, D.E., Watson, N.W., Pierson, K.E., \& Van Citters, R.L. Technique for radiotelemetry of blood from unrestrained animals. Amer. J. Med. Electronics 5: 24 (1966).

6. VATNER, S.F. \& SMith, N.T. Effects of halothane on left ventricular function and distribution of regional blood flow in dogs and prinates. Circ. Res. XXXIV, 155 (1974).

7. Vatnen, S.F., Franklin, D.E., \& Van Citters, R.L. Simultaneous comparicon and calibration of the Doppler and electromagnetic flowmeters. J. Appl. Physiol. 29: 907 (1970).

8. Bastron, R.D. \& Kaloyantoes, G.J. Effect of sodium nitroprusside on function in the isolated intact dog kidney. J. Pharmacol. Exp. Ther. 181: 244 (1972).

9. WANG, H.H., Liv, L.M.P., \& KATZ, R.L. A comparison of the cardiovascular effects of sodium nitroprusside and trimethaphan. Anesthesiol. 46: 40 (1977).

10. BLAKE, W.D. Some effects of pentobarbital anaesthesia on renal hemodynamics, water and electrolyte excretion in the dog. Amer. J. Physiol. 191: 393 (1957).

11. Burcer, B.M., Hopkins, T., Tulloch, A., \& Hollenbers, N.K. The role of angiotensin in the canine vascular response to barbiturate anesthesia. Circ. Res. 38: 196 (1976). 